Revista de Economia Política, vol. 30, $n^{\circ} 4$ (120), pp. 625-644, outubro-dezembro/2010

\title{
Método dinâmico da Escola de Estocolmo
}

\author{
FERNANDO NOGUEIRA DA COSTA*
}

Dynamic method of the Stockholm School. The development of the dynamic method is considered the biggest contribution of the Stockholm School. The objective of this review-article is to show as this method contributed for the Alternative Theory of Money. The influence received from Wicksell is argued. The Stockholm School anticipated the thought of Keynes, but advancing dynamic macroeconomic analysis. The restatement of Keynes'ideas, under the dynamic method, is important post Keynesian contribution.

Keywords: School of thought; dynamic method; ex antelex post.

JEL Classification: B20; B41; B59.

\section{INTRODUÇÃO}

A existência da Escola de Estocolmo foi mencionada pela primeira vez, em artigo em inglês, por Ohlin (1937a). O artigo foi publicado na principal revista de Economia da época, Economic Journal, cujo editor era o próprio Keynes, a quem eram dirigidas críticas metodológicas na elaboração de sua Teoria Geral e, especialmente, de sua teoria da taxa de juros. Ele publicou sua "resposta" (Keynes, 1937a) - Alternative Theories of the Rate of Interest - em seguida à segunda parte do artigo de Ohlin, este replicou (1937b) e, em número posterior, Keynes (1937b) apresentou sua "tréplica". Face a essa controvérsia, os economistas leitores de língua inglesa tiveram então seu interesse despertado pelo desenvolvimento da teoria econômica na Suécia, ocorrido após a morte de Wicksell, em 1926.

Entretanto, esta mobilização de atenções ficou marcada pelo "vício de ori-

\footnotetext{
* Professor adjunto/livre-docente, Instituto de Economia, Universidade Estadual de Campinas — Unicamp. E-mail: fercos@eco.unicamp.br. O autor agradece os comentários críticos e as sugestões do parecerista anônimo, todos eles pertinentes e incorporados na revisão final do texto. Submetido: Dezembro 2008; Aprovado: Junho 2009.
} 
gem": os estudos sobre a Escola de Estocolmo privilegiaram a comparação com a teoria macroeconômica de Keynes. A recorrente discussão foi se os autores suecos - Myrdal, Lindahl, Lundberg, Hammarskjöld e Ohlin —, construindo sobre fundações wicksellianas, desenvolveram corpo de análise que era, embora separado, paralelo ao associado com o nome de Keynes.

"É fato digno de menção, na história da análise econômica, que [...] este desenvolvimento efetuou-se paralelamente, e sob alguns aspectos antecipou-se aos ingleses (keynesianos), sem se tornar conhecido dos economistas ingleses. Resultaram daí, naturalmente, alguns protestos platônicos e também algumas discussões sobre os métodos relativos das duas correntes de pensamento" (Schumpeter, [1954] 1964, vol. 3, p. 392).

Hansson (1991, pp. 168-213) focalizou esse capítulo na história do pensamento econômico sueco, com o objetivo de analisar essa Escola sob ângulo diferente. Disse ele (1991, p. 168): "o desenvolvimento do método dinâmico é considerado a differentia da Escola de Estocolmo".

Uma "escola" é definida em torno do desenvolvimento inter-relacionado de tema comum entre seus membros: no caso, a explícita atenção ao desenvolvimento do método dinâmico. Este se refere às noções tais como equilíbrio temporário e análise sequencial de desequilíbrios. A discussão do método dinâmico se distinguiu como contribuição original, caracterizando a existência de escola distinta - a Escola de Estocolmo -, entre 1927 e 1937. A partir deste ano, com a publicação de Studies in the Theory of Economic Expansion, de Lundberg (1937), os trabalhos ganharam considerável extensão além da fronteira sueca, inclusive com cooperação de autores estrangeiros, e da preocupação estrita com o método dinâmico, embora obviamente baseados nesta abordagem.

Os discípulos suecos jamais deixaram de apresentar-se como wicksellianos, mesmo quando o criticaram e o ultrapassaram. Seus trabalhos representam o desenvolvimento pós-wickselliano. Entretanto, é comumente pensado que a Escola de Estocolmo cresceu apenas a partir da herança teórica deixada por seu presumido ancestral sueco: Wicksell. Embora isto seja verdade para as questões macroeconômicas, Hansson (1991, p. 169) argumenta que a influência de Wicksell sobre a característica distinta da Escola de Estocolmo, o método dinâmico, é insignificante. Mesmo o processo cumulativo, tal como desenvolvido originalmente, não foi seu ponto de partida imediato.

Por outro lado, a relação da Escola de Estocolmo com a chamada "Revolução Keynesiana”, principalmente, o princípio da demanda efetiva, tem sido visto como longo enigma na história do pensamento econômico. A questão seria mais bem enfrentada partindo do pressuposto que a Escola de Estocolmo desenvolveu sua maneira de encarar esse princípio independentemente. Hansson (1991, p. 190) mostra que, embora a análise sueca contenha elementos que são similares ao prin- 
cípio da demanda efetiva, por exemplo, a taxa de juros nem sempre equilibra poupança e investimento, aquele princípio é sempre usado em abordagem de desequilíbrio.

Também não é bem fundada a visão dominante entre os historiadores do pensamento econômico de que a Escola de Estocolmo teve morte súbita em função da publicação da Teoria Geral por Keynes em 1936. Na verdade, argumenta Hansson (1991, pp. 169/170), quando a utilização e as contribuições para a evolução de sua metodologia ultrapassaram as fronteiras suecas, deixou de ter sentido sua denominação local.

Seus principais autores também ultrapassaram outra fronteira, no caso, a do campus universitário e/ou da elaboração apenas teórica. Embora Gunnar Myrdal (1898-1987) tenha seguido distinta carreira na academia, sendo professor entre 1933 e 1950 e, depois, entre 1960 e 1967, ele não se alienou da política. Foi deputado pelo Partido Social-Democrata em 1935-1938 e 1944-1947. Depois de sua contribuição teórica, passou a estudar, em 1938, os problemas dos negros norte-americanos, até publicar, em 1944, o livro An American Dilemma: The Negro Problem and Modern Democracy. Neste livro analisou a "causalidade cumulativa", ou seja, a pobreza gerando mais pobreza. Em seus trabalhos sobre economia do desenvolvimento, Myrdal alertou que o desenvolvimento econômico das nações ricas e o das nações pobres, deixados às forças do livre mercado, dificilmente convergiriam. Em 1968, publicou Asian Drama. De 1947 a 1957, Myrdal foi secretário executivo da Comissão Econômica das Nações Unidas na Europa. Em 1974, compartilhou com Friedrich von Hayek o Prêmio Nobel de Economia.

Erik Robert Lindahl (1891-1960) foi o único membro da Escola de Estocolmo que teve somente carreira acadêmica. Sua tese de doutorado foi em grande extensão baseado em ideias wicksellianas. Ele teve contacto com Wicksell, mas não foi seu estudante.

Erik Filip Lundberg (1907-1987) tirou seu Ph.D. em 1937. Neste mesmo ano, tornou-se o primeiro diretor do Instituto Governamental de Pesquisa Econômica (1937-1955). A partir de 1946, tornou-se professor universitário.

Dag Hjalmar Agne Hammarskjöld (1905-1961), filho de Primeiro Ministro Sueco (1914-1917), obteve seu doutorado em 1933, Participou ativamente das discussões do grupo até 1936, quando iniciou sua carreira no Ministério das Finanças. Foi diretor do Banco da Suécia (1941-1948), antes de ser eleito Secretário Geral da ONU (1953-1961). Em 1961, morreu em acidente aero na Zâmbia, onde estava desempenhando missão da ONU. Foi, postumamente, premiado com o Prêmio Nobel da Paz.

Bertil Gotthard Ohlin (1988-1979) também dividiu Prêmio Nobel em Economia, com James Meade, em 1977, por suas contribuições à teoria do comércio internacional. Este foi o tema de sua tese de doutorado em 1924, orientada por Gustav Cassel. Foi professor universitário (1929-1965). Nos anos 40's, suas ativi- 
dades como político tomou mais seu tempo: líder do Partido Liberal (1944-1967) e membro do Gabinete (1944-1945).

O objetivo deste artigo-resenha é mostrar como o método dinâmico da Escola de Estocolmo contribuiu para a formulação de Teoria Alternativa da Moeda (Costa, 1999, pp. XIII-XX; 3-32), cujos postulados são: a instabilidade da velocidade da moeda, a validação monetária de decisões econômicas e financeiras, a oferta de moeda endógena e a não neutralidade da moeda. Esta importa em decisões ex ante que têm resultados ex post muitas vezes inesperados. Além desta Introdução e da Conclusão, haverá quatro seções. Na próxima, apresenta-se a classificação realizada por Hansson (1991, pp. 173-177) dos diferentes métodos dinâmicos desenvolvidos por esses autores suecos. Após, examina-se mais detalhadamente as contribuições de Myrdal (1931). Na quarta seção, coloca-se ênfase na argumentação de Shackle (1965, 1966, 1967, 1972), porque ela articula a Escola de Estocolmo e a Escola Pós-Keynesiana. Na quinta, há a sugestão de releitura da obra de Keynes de acordo com o método dinâmico dos pós-wicksellianos.

\section{MÉTODOS DA ESCOLA DE ESTOCOLMO}

Hansson (1991, p. 170) divide o período de existência da Escola de Estocolmo em quatro distintos estágios. Cada estágio é caracterizado por um específico método dinâmico.

O primeiro estágio é referente ao método da tese de doutoramento de Myrdal, defendida em 1927, a qual mostra como as tentativas de antecipações do futuro incerto constituem parte independente dos dados que são supostos determinantes de posição de equilíbrio em longo prazo. O fator crucial para o posterior desenvolvimento da Escola de Estocolmo foi o tratamento das antecipações e incertezas como parte do âmago teórico, inclusive sua colocação no mesmo nível das preferências, condições técnicas e recursos disponíveis.

A construção inicial de Lindahl (1929) do equilíbrio intertemporal constitui o segundo estágio. Este conceito surgiu a partir da crítica da estática comparativa como instrumento para manipulação de problemas dinâmicos. Seu objetivo foi descrever a travessia entre duas posições de equilíbrio estacionário. Siven (2002, p. 116) destaca que o artigo The Place of Capital in the Theory of Price, publicado em sueco em 1929 e quase todo traduzido para publicação, no ano de 1939, do sumário em inglês das contribuições desse autor, "é talvez o mais importante trabalho de Lindahl em teoria econômica. Ele contém o primeiro desenvolvimento sistemático de teoria microeconômica intertemporal”. Hicks (1965, p. 58) reconhece a influência desse método dinâmico desenvolvido por Lindahl, em 1929, sobre sua obra Value and Capital, publicada em 1939.

O terceiro estágio refere-se ao equilíbrio temporário, quando se analisa o 
processo cumulativo. Entretanto, tanto o equilíbrio intertemporal como o equilíbrio temporário ainda seguem a abordagem de equilíbrio. Lundberg ([1937] 1955) e Myrdal (1931) criticaram este enfoque, desde que ele não pode explicar a ligação entre períodos consecutivos.

O equilíbrio intertemporal é um caso especial do equilíbrio temporário. Segundo Siven (2002, p. 130), "para o equilíbrio temporário existir, as ações dos indivíduos somente podem ser coordenadas no período corrente. Se economia em equilíbrio intertemporal é afetada por algum distúrbio, pode-se levar muitos períodos antes dos agentes adquirirem o conhecimento necessário a respeito do novo contexto e então elaborarem a prospectiva correta, necessária para o equilíbrio intertemporal ser (ou não) alcançado. Durante essa transição haverá equilíbrio temporário em cada período".

O último estágio, ainda segundo Hansson (1991, p. 171), culminou em 1937 com a análise sequencial de desequilíbrio, elaborada por Lundberg. Esta noção foi precedida por longo e protelado desenvolvimento. Myrdal foi quem lhe deu início e o direcionou, corretamente, com a publicação do livro Monetary Equilibrium (original sueco em 1931), o qual lançou a fundação para a abordagem de desequilíbrio com as noções de ex ante e ex post.

A análise sequencial é um tipo de método dinâmico, para o qual o tempo dos eventos econômicos é de suprema importância. A questão é se, seguindo seu procedimento, é possível determinar com certeza o resultado de alguns períodos adiante no tempo. Sendo este irreversível, não há "viagem de ida e volta ao futuro".

A ideia central, na análise sequencial sueca, é a noção que cada plano individual condensa certo comportamento econômico, o que significa que todas as ações econômicas direcionadas ao cumprimento de planos são baseadas em expectativas do futuro e que estes planos serão revisados à luz dos reais resultados. Planos de diversos agentes econômicos, incongruentes entre si, conduzirão à formação de novos planos. Daí o crucial papel das expectativas, desde que representam a conexão entre eventos precedentes e novos planos.

Não necessariamente haverá equilíbrio em períodos vindouros, no sentido que planos para estes períodos futuros, feitos no início de cada período corrente, serão consistentes entre si e com a disponibilidade de recursos. Por isto, constata-se o caráter puramente temporário de eventual equilíbrio.

Segundo Siven (2006, p. 700), "Myrdal (1931) era muito crítico acerca do método do equilíbrio temporário de Lindahl (1930). Sua principal objeção foi que o pressuposto de coordenação no início de cada período e de negociações com base em preços fixos na parte restante do período era irrealista. Myrdal, consequentemente, argumentou a favor de adoção de análise de desequilíbrio. Isto significa que as ações e as expectativas dos agentes não são coordenadas através de preços ou racionamento de quantidades. As pessoas terão surpresas durante o período. Os valores ex ante, consequentemente, diferirão dos valores ex post". 
O método de desequilíbrio analisa períodos fora de equilíbrio, o que significa que os planos ex ante não são consistentes, mas os valores ex post são igualados. Esse método implica em análise sequencial de desequilíbrio e de equilíbrio.

Em comparação com as várias tentativas antes referidas de formular a teoria dinâmica, a primeira parte de Lindahl (1939) — e terceira parte na edição espanhola (1946) - contém tratamento mais sistemático. Em Introduccion al Estudio de la Teoria Dinamica de Lindahl (1946, pp. 207-249), ele sublinhou como a análise dinâmica tanto do comportamento individual, quanto dos resultados do mercado, em princípio, deve ser desenvolvida. Esta análise micro e macroeconômica poderia ser realizada seja supondo equilíbrio seja desequilíbrio.

No Prólogo a La Edición Española, escrito por Lindahl (1946, pp. XXI-XXIV)), ele afirma que "só considerando os fenômenos econômicos como produto dos esforços humanos, nos será possível compreendê-los. Portanto, o ponto de partida do investigador econômico residirá nos planos dos sujeitos econômicos".

Quando na comunidade existem muitos agentes econômicos, existirão muitos planos distintos em ação. Partindo dos planos vigentes em certo ponto do tempo, o economista pode explicar as ações que se apresentam e a totalidade do desenvolvimento como resultado das mesmas e dos fatores exógenos. Porém, o período durante o qual todos os planos permanecem invariáveis terá que ser, forçosamente, muito curto. O período de planos invariáveis terá que ser computado em dias, quando se trata de comunidade dotada de liberdade de ação econômica.

"Se analisamos toda uma série de períodos curtos, veremos que durante alguns deles os preços e as quantidades vendidas se correspondem entre si, não só desde o ponto de vista dos compradores, mas também dos vendedores. Neste caso, existe interdependência mútua entre ditas magnitudes ao longo do período. Por conseguinte, podemos falar de um equilíbrio de período curto no mercado. Em outros períodos, as expectativas dos vendedores ou dos compradores não se cumprem [...]. E o desvio entre as expectativas e o curso real dos acontecimentos pode dar motivo inclusive a que se modifique o plano. Os fabricantes, por exemplo, estimam que a demanda de seus produtos não é tão elevada como a que eles haviam suposto, vendo-se na obrigação de rebaixar seus preços. Em tal caso, podemos falar de um desequilíbrio de período curto" (Lindahl, 1946, p. XXII).

Quando os acontecimentos imprevistos que surgiram durante o período originaram mudança nos cálculos individuais, a renda e o investimento, calculados ao final de um período como magnitudes retrospectivas, não coincidirão, logicamente, com as expectativas estabelecidas no começo do mesmo. Deste modo, Lindahl (1946, p. XXIII) chega à "distinção ex-ante e ex-post, para empregar os conceitos que agora estão na moda entre os economistas suecos”. Este método, segundo ele, "permite explicar o movimento, ao menos parcialmente, como resultado do desequilíbrio observado nos períodos estudados".

Em sua tese de doutoramento, Myrdal segue o método das expectativas. Inclui 
antecipações como parte dos dados que são, imediata ou primariamente, determinantes dos preços. Entretanto, a mais relevante contribuição para o desenvolvimento do método dinâmico da Escola de Estocolmo foi a construção das noções de ex ante e ex post. Com estas noções, é possível empreender a análise de desequilíbrio.

Porém, na opinião de Siven (2006, p. 702), “a questão de saber se a Escola de Estocolmo antecipou (ou mesmo ultrapassou) a análise da Teoria Geral de Keynes está conectada com a questão de saber se os economistas suecos realizaram análise de desequilíbrio ou não. Uma das razões pelas quais Keynes constituiu - e a Escola de Estocolmo não - o ponto de partida para o desenvolvimento da macroeconomia durante as décadas seguintes foi a de que Keynes, justamente, formulou um modelo de equilíbrio. Aos economistas de Estocolmo, geralmente, faltava o adequado método analítico para executar análise de desequilíbrio. As típicas análises de desequilíbrio realizadas em Estocolmo foram geralmente transformadas em análises de casos especiais. Seus princípios gerais não eram fáceis de se distinguir. Em contrapartida, a estrutura clara e de fácil compreensão da interdependência de modelos de equilíbrio trabalharam em favor dos keynesianos”.

A característica comum entre todas as teorias da Escola de Estocolmo é o óbvio desinteresse na análise de equilíbrio e a preferência pela, nas palavras de Steiger (1989, p. 227), “casuística análise de desequilíbrio”. Leijonhufvud (1989, p. 269) também a critica: "As tentativas realizadas pela Escola de Estocolmo para melhorar o tratamento das expectativas por Wicksell foram menos bem-sucedidas, mas produziram uma marca de análise de processo geral no qual quase tudo podia acontecer". O repúdio à noção de equilíbrio localmente estável é o ponto de maior divergência.

\section{ABORDAGEM EX ANTE / EX POST DE DESEQUILÍBRIO}

O Equilíbrio Monetário, livro de Myrdal publicado em sueco, em 1931, e em inglês, em 1939, foi tentativa de reconstrução crítica da noção de "taxa de juros normal", elaborada originalmente por Wicksell. Seu ponto de partida foi a análise de Lindahl, realizada no ensaio A Taxa de Juros e o Nivel de Preços, em 1930, republicado, em 1939, na Primeira Parte do seu livro Estudos sobre a Teoria do Dinheiro e do Capital.

O conceito de "taxa de juros normal" de Wicksell deveria cumprir, como inicialmente mostrou Lindahl, três diferentes condições para se atingir o equilíbrio monetário: primeiro, igualar à "taxa natural ou real”; segundo, equalizar investimento esperado e poupança; terceiro, preservar o nível geral dos preços estável. Em seus desenvolvimentos da análise de Wicksell, tanto Lindahl quanto Myrdal criticaram a consistência desta tríplice condição, conduzindo ao abandono da noção de "taxa normal" por Lindahl e à reformulação por Myrdal. 
Myrdal distingue entre resultados esperados, a que denominou ex ante, e categorias passadas, ou ex post. Desta forma, o investimento ex ante é o investimento planejado para período vindouro, baseado em renda ex ante ou planejada, A poupança ex ante se baseia também em renda e consumo futuros esperados. A poupança, o investimento e a renda ex post foram realizados, durante período passado, e, assim, poderiam ser, em princípio, examinados mediante registros estatísticos.

"Para explicar as flutuações econômicas, é necessária uma análise ex ante. Devem-se examinar expectativas e planos para o futuro. Enquanto as expectativas e os planos se baseiam até certo ponto em experiências e condições presentes ou passadas, não há uma conexão direta entre as duas" (Oser \& Blanchfield, 1989, p. 403). O ocorrido no passado não garante que ocorrerá o mesmo no futuro: o passado não predetermina o futuro, pois este depende de múltiplas decisões, no presente.

No cálculo ex post, verifica-se a ocorrência (ou não) do exato balanço entre o investimento esperado e o valor do investimento bruto realizado. No cálculo ex ante, a questão não se refere aos resultados realizados, mas às expectativas, cálculos e planos dirigidos ao processo dinâmico futuro.

Myrdal ([1931], 1946, pp. 46-47) enfatiza que "uma importante distinção existe entre métodos prospectivos e retrospectivos de cálculo de quantidades econômicas, tais como renda, poupança, e investimento; e que uma correspondente distinção de grande importância teórica deve ser desenhada entre dois métodos alternativos de definir estas quantidades: 1. quantidades definidas em termos de medidas realizadas ao fim do período em questão são referidas como ex post; 2 . quantidades definidas em termos de ação planejada no início do período em questão são referidas como ex ante. A análise monetária deve usar ambos sistemas de definição e examinar sua inter-relação, se é para fazer algum progresso. [...] Provavelmente, a principal contribuição deste ensaio, se há alguma, é ter originado os conceitos ex post e ex ante; e ter enfatizado a importância de claramente reconhecer o período implícito na análise monetária”.

O problema real a ser resolvido na teoria monetária, para Myrdal, é: como a tendência à disparidade na equação investimento-poupança se desenvolve no balanço ex post? Como ele mostra, a rota vai sobre elementos puramente dinâmicos de ganhos e perdas, os quais não entram explicitamente nos cálculos ex ante, pois são, de fato, causados por mudanças nas antecipações. Eles constituem espécie muito particular de custos e receitas nos cálculos ex post.

"A causa geral da existência de uma diferença entre os dois [cálculo ex ante e cálculo ex post] é o fator de incerteza no cálculo das antecipações. O processo técnico da produção requer tempo: durante este tempo, mudanças ocorrem sem que sejam antecipadas com absoluta certeza. Resultam em ganhos e perdas. Estes ganhos e perdas não são, em princípio, nem elementos de renda, nem receita ou 
custo; nem tampouco são valores de capital. Eles não são preços, mas variações de preços” (Myrdal, [1931] 1946, pp. 59-60).

O conceito de "equilíbrio monetário", segundo Myrdal, sempre concerne à tendência idealizada de determinada situação em algum ponto particular do tempo futuro. Mas as quantidades envolvidas devem ser definidas ex ante.

O equilíbrio monetário, de acordo com o segundo critério de Wicksell, considerado válido por Myrdal, é entendido como a igualdade entre o investimento ex ante e a "disposição de capital livre", ou seja, a soma da poupança com as variações do valor do ativo de capital antecipadas. Para caracterizar o equilíbrio, é necessário, então, fluxo de investimento, estimulado pelas taxas de rentabilidade esperada, ou seja, a reação dos empresários ao lucro previsto, compatível com o volume de poupança. Esta é, justamente, a parcela dessa renda não destinada ao consumo imediato. A poupança, portanto, possui caráter monetário.

Myrdal procura caracterizar a condicionalidade do equilíbrio monetário, mostrando inclusive a possibilidade de divergência ex ante e resolução ex post. "Myrdal analisa a possibilidade de divergência entre o investimento e a poupança mediante uma série de exemplos abstratos nos quais a alteração das expectativas ou da taxa de juros gera uma discrepância entre essas magnitudes agregadas" (Soromenho, 1986, p. 120).

A independência entre as decisões de investir e de poupar fica então caracterizada. Ex ante, o desequilíbrio no mercado de fundos é logicamente possível. Os recursos financeiros suplementares demandados pelos investidores são supridos pelo sistema bancário, através de sua capacidade de criação de crédito ex nibilo, sem que, necessariamente, haja elevação da taxa de juros monetária.

Ex post, a cada período unitário do processo cumulativo, a poupança e o investimento efetivamente realizados devem ser iguais. Em Monetary Equilibrium, essa igualdade é obtida através de ganhos e perdas não esperados pelos agentes econômicos. No entanto, Myrdal mostra não ser possível identificar os agentes cuja poupança ex post corresponde ao acréscimo de investimento real, pois a renda real ex post e a sua parcela poupada pelos diversos agentes não é determinada em nível microeconômico, mas sim macroeconômico. "Porém, dois aspectos do pensamento de Myrdal são expressos claramente: primeiro, é a poupança que, de modo geral, ajusta-se ao nível de investimento almejado; e, segundo, a alteração exógena das expectativas resulta na frustração ex post de demandas e ofertas formuladas com base em antecipações não mutuamente consistentes - a descoordenação das ações dos agentes econômicos é trazida para o momento presente" (Soromenho, 1986, p. 124).

Soromenho observa também que, evidentemente, é possível questionar a coerência lógica do raciocínio de Myrdal sob o ponto de vista estritamente atomista. Lembra que a busca dessa coerência foi objeto de investigações da literatura de macroeconomia do desequilíbrio, na qual se procurava distinguir entre demandas nocionais e efetivas, mas essa agenda de pesquisa, praticamente, desapareceu. 
A conclusão mais importante desse intérprete do pensamento sueco é que a reformulação do conceito de equilíbrio monetário através das categorias ex ante e ex post proporciona a Myrdal resultados distintos dos encontrados na teoria de Wicksell. A análise do mercado de capitais permite estabelecer a possibilidade de discrepância entre a poupança e o investimento e sua resolução ex post. A moeda creditícia é não neutra. Ela pode ser passiva, quando sanciona alterações do sistema econômico provindas de mudanças de expectativas. Nesse sentido, a moeda creditícia simplesmente acomoda (ou não) decisões econômicas (de produzir, de investir, de consumir, de formar estoques, de fixar preços etc.) tomadas no chamado setor real. Se o sistema bancário aumentar o volume de crédito, através da diminuição da taxa de juros de mercado, ou vice-versa, de qualquer forma, as alocações reais serão afetadas.

O critério de equilíbrio monetário, no entanto, não determina o sistema econômico como um todo. Na teoria de Myrdal, esse conceito se refere somente aos agregados macroeconômicos.

Outros comentários críticos são realizados por Myrdal ([1931], 1946, pp. 206-207) a respeito da teoria de Wicksell. Por exemplo, acha que elementos monopolísticos podem (e devem) ser prontamente incorporados. O grande obstáculo para a análise prática baseada nesta teoria é geralmente apresentada pela diferença entre efeitos de "curto prazo" e de "longo prazo". Tem que se trabalhar combinações de condições de crédito. Há ainda a dificuldade baseada no fato que não somente a política monetária, mas também todas as outras políticas econômicas atuam sobre a posição de equilíbrio. Por fim, destaca o problema surgido de "complicações internacionais". A teoria de Wicksell é válida, primariamente, para "economia fechada". É aplicável diretamente, em análise geral, em termos de economia mundial, somente se as fases do ciclo de negócios se sincronizam, justamente, em todas as partes do mundo. Embora seja, obviamente, teoria muito formal, não contém elementos que a excluem da possibilidade de reparos e adaptações em todos os pontos, em correspondência com os fatos observados. Por isso que é cientificamente tão frutífera.

A terceira condição, para o equilíbrio monetário, no sistema de Wicksell, está relacionada com as condições do mercado de bens. A taxa de juros normal é aquela taxa monetária capaz de estabilizar o nível geral dos preços dos bens finais. No entanto, Myrdal mostrou que as condições de equilíbrio, em si, só permitem algum movimento do nível dos preços absolutos, desde que este movimento seja perfeitamente uniforme para diferentes preços. Em outras palavras, sem alteração de preços relativos.

Realisticamente, para Myrdal, essa hipótese é insustentável. Em primeiro lugar, há contratos de crédito, estipulando taxa de juros fixas, e outros contratos, com taxas flutuantes, que se estendem ao longo do tempo. Em qualquer movimento do nível geral dos preços, que não tenha sido antecipado com plena certeza por todos 
aqueles que tomem parte na formação de preço, a distribuição de rendas e propriedades deve necessariamente mudar. Consequentemente, a demanda e a oferta de diferentes mercadorias variam, assim como suas relações de preços, inclusive a relação específica de preços relevante para se atingir equilíbrio monetário.

Mas há um elemento geral de inércia no ajustamento do sistema econômico às primeiras variações. Alguns preços reagem mais rapidamente e outros mais vagarosamente. Ademais, sob monopólio, ou em mercados com pequeno número de grandes competidores, preços existentes são, frequentemente, administrados pela política de manutenção de preços mesmo que ocorram violentas mudanças na demanda.

Myrdal ([1931], 1946, p. 135) mostra, assim, a inércia na formação dos preços e a inflexibilidade desses preços administrados como restrições impostas sobre o sistema de preços. "Uma política monetária apontada para preservar as relações de equilíbrio deve, portanto, adaptar os preços flexíveis ao nível absoluto dos fixos [sticky]".

No caso da hipótese em que todos os indivíduos antecipam todas as variações dos fatores primariamente determinantes de preços, e todos os efeitos dessas variações, os agentes econômicos tornam-se independentes dos fatores de inércia. Mas, na realidade, há sempre incerteza a respeito dos dados futuros. Desde que todas as reações de formação de preços levam tempo, as condições de equilíbrio fornecem, para Myrdal, em função dessas duas razões, apenas referências abstratas para a evolução do nível geral dos preços.

"Rigidez menor dos preços de diferentes bens e serviços, e para os mesmos bens e serviços em vários mercados, depende de diferentes circunstâncias institucionais - lei, convenção, hábitos de consumo, métodos de produção, padrões de propaganda, políticas de preços, todo tipo de elemento monopolístico, e várias outras circunstâncias - que determinam as condições de reação para preços em diferentes mercados: condições relacionadas não somente com a oferta e a demanda, mas também com o preço de oferta e o preço de demanda" (Myrdal [1931], 1946, p. 135).

O nível geral dos preços, sob hipotético equilíbrio monetário, deve ter então essa tendência. Ela permitiria o cumprimento das condições de equilíbrio das relações de preços com a menor possível variação dos preços rígidos.

Em sua investigação da terceira condição de Wicksell — preservar o nível geral dos preços estável —, Myrdal concluiu, portanto, que o equilíbrio monetário é determinado pelas duas primeiras condições mais fundamentais, ficando essa terceira condição em segundo plano. A variação uniforme em todos os preços monetários não afetaria nenhum investimento nem perturbaria o equilíbrio no mercado de capitais, desde que os agregados monetários variassem na mesma proporção. Mas as variações nos componentes do nível geral dos preços não são uniformes. Na realidade, alguns preços monetários, como valores de capital, são 
altamente flexíveis, enquanto outros, especialmente salários, são muito rígidos. Estes últimos colocariam restrição sobre o sistema de preços.

Concluindo que a terceira condição é privada de significado, para a determinação do equilíbrio monetário, Myrdal salienta, no entanto, que ela poderia ser usada como norma para política monetária, objetivando restaurar eventual distúrbio. Isto não significa estabilização do nível geral dos preços, mas sim mitigação do ciclo de negócios, trazida pela adaptação dos preços flexíveis aos mais rígidos. Poderia ser alcançado pela estabilização do índice daqueles preços que são, em si, rígidos. Na prática, significaria manter estabilidade de salários, enquanto se movem os valores dos ativos do capital.

Essa aparente solução de Myrdal, naturalmente, recebe crítica. "Em contraste com Wicksell, que assumiu competição pura em todos os mercados, Myrdal relaxou esta hipótese para tomar conhecimento do fato de que a maioria das firmas em economia moderna atua nos mercados variando graus e severidade da competição imperfeita. Esta reconstrução por Myrdal das condições de equilíbrio de Wicksell parece realística e plausível, até que nos perguntamos como a adaptação dos preços flexíveis aos níveis dos inflexíveis é alcançada. Para isto, ele não ofereceu nenhuma resposta" (Uhr, 1962, p. 98).

\section{ESCOLA DE ESTOCOLMO E ANTECIPAÇÃO A KEYNES}

De acordo com Hicks ([1965] apud Hansson, 1991, p. 211), é possível falar de duas diferentes revoluções nos anos 1930. "Passar de um puro método a outro [flex-price para fix-price] é quase uma revolução. [...] entre seus dois trabalhos [Treatise on Money e General Theory], Keynes moveu-se na direção do novo método. [...] uma correspondente mudança ocorreu na Suécia. A forma original (1929-1930) da teoria de Lindahl [...] era puro equilíbrio temporário. Mas no Monetary Equilibrium (1933), como indica o título, a mudança é iniciada. $\mathrm{Na}$ Economic Expansion (1937) está justamente completa. No último trabalho de Lindahl [...] ele também se moveu na mesma direção".

A primeira revolução teórica se referiu aos métodos dinâmicos. Neste campo, a Escola de Estocolmo teve o maior papel. A outra foi a revolução keynesiana, em sentido estrito, isto é, o princípio da demanda efetiva. Nesta perspectiva, segundo Hansson (1991, p. 212), a contribuição de Keynes na General Theory e a contribuição da Escola de Estocolmo são mais complementares do que antagônicas.

Por isso, não haveria razão de se dizer que a Escola de Estocolmo foi extinta pela revolução keynesiana. Mesmo porque alguns dos métodos dinâmicos desenvolvidos pelos suecos tornaram-se parte da apresentação da mensagem keynesiana pelos autores pós-keynesianos. Por exemplo, o modelo gasto-renda analisa as decisões de gastos e as acomodações em estoques (e quantidades) via as noções de $e x$ ante e expost. 
Interessante também é a posição de Hicks ([1977] 1978, pp. 82-84) a respeito da reinterpretação da doutrina de Wicksell por seus sucessores, seja a realizada pela Escola de Estocolmo, seja pelos keynesianos. Hicks coloca a questão: como a taxa natural pode ser taxa real, que deve ser expressa em algum conjunto de bens, e ser comparada à taxa de juros de mercado, que deve ser expressa em termos de moeda?

Para essa questão, há várias saídas. Há a saída de Keynes, pela qual aquilo que tem que ser comparado com a taxa de juros de mercado não é a taxa real de Wicksell, mas a eficiência marginal do capital, ela própria sendo taxa monetária. Ela é influenciada não só pelos fatores reais de Wicksell, mas também por expectativas sobre os preços e até, de modo mais geral, pelo estado de espírito dos empresários. Outra saída seria à maneira dos sucessores de Wicksell. Hicks cita, entre estes, Lindahl, Myrdal e parte de sua própria obra Value and Capital de 1939 e Capital and Growth de 1965. Neles, há a conversão do modelo de Wicksell em modelo sofisticado de equilíbrio temporal, tornando o investimento corrente dependente de expectativas e o equilíbrio a condição fugaz em que as expectativas não são desapontadas.

Em sua fase de autocríticas, Hicks passou a achar que essas interpretações extrapolaram o modelo de Wicksell. Quando se olha Wicksell à luz de seu problema e de sua própria experiência, seguramente, ele deveria ser interpretado de forma mais simples, e não com viés em expectativas. A geração posterior de economistas acha fácil tal interpretação; mas atribuí-la a Wicksell, em sua época, é provavelmente anacronismo. Portanto, quando se coloca esse autor em seu contexto histórico, Hicks acha que essa reinterpretação não está muito certa em termos de história do pensamento econômico.

Shackle ([1965], 1969, p. 61) possui outra interpretação. A Keynes teria parecido necessário usar uma construção de equilíbrio para discutir as consequências da ignorância a respeito do futuro e da incompatibilidade mútua das expectativas sustentadas por um ou por outro grupo de agentes econômicos. No entanto, “já existia, quando Keynes estava escrevendo a sua Teoria Geral, uma construção que, assim o cremos, melhor atenderia ao seu propósito. Os discípulos de Knut Wicksell, principalmente Erik Lindahl e Gunnar Myrdal, propuseram-se, no fim da década de 1920, examinar, de um ponto de vista totalmente simpático e dir-se-ia mesmo de fidelidade filial, o famoso Processo Cumulativo do seu mestre Wicksell no qual as expectativas dos homens de negócios os levam a ações que, no conjunto dos seus resultados, falsificam aquelas expectativas em dada direção e assim induzem novas expectativas que sofrem, novamente, processo de autofalsificação na mesma direção e assim por diante. O processo de Wicksell referia-se ao nível geral dos preços e não ao vulto do produto geral ou ao nível de emprego, mas sua ideia essencial, que Myrdal e Lindahl tornaram explícita, era aplicável a qualquer espécie de ação e de resultado". 
Essa ideia consiste, simplesmente, em distinguir os acontecimentos e as situações "que se esperavam", em intervalo ainda futuro, e os acontecimentos e as situações "que de fato surgiram", no registro desse intervalo, depois que ele foi incorporado pela história. Myrdal denominou essa concepção dos conteúdos de um segmento de tempo, que alguém pode conceber quando no limiar desse segmento, apreciação ex ante, enquanto o que foi, de fato, registrado, quando passado o intervalo, é chamado de apreciação ex post.

O tema da General Theory requer, para Shackle, a linguagem de ex ante e ex post, pois se trata de teoria da decisão, e a decisão é ex ante. Faz referência ao intervalo de tempo no futuro, no concernente ao qual, no presente, só podem haver intenções, planos ou decisões. Dependerão, para sua realização, da compatibilidade de uns com outros, e com o curso da natureza não humana, assim como com a conduta humana não deliberada, de cada momento. Para esse autor, não existe "nenhum nexo" entre essas ficções, às quais chamamos de "expectativas", inventadas por uma pessoa ou grupo de pessoas, e as inventadas por outra ou outro.

A taxa natural é, segundo Shackle ([1972] 1976, p. 356), “um composto de expectativas, de pensamentos originais, sugeridos meramente por correntes de impressões, diversamente recebidas por diferentes indivíduos. É esta natureza das expectativas, evasiva e por demais sutis, o que obrigou ao teórico da economia, em sua tarefa de simplificação, mediante abstração, a excluí-las totalmente ou a escondê-las em uma 'caixa-preta', como é a taxa de juros natural ou a eficiência marginal do capital. O tratamento que recebem é arbitrário. Não pode descansar na lógica mediante a qual se determina rigidamente o equilíbrio geral, essa imagem de racionalidade".

A expressão "taxa natural" sugere produtividade determinada tecnologicamente. Myrdal descartou esta noção em favor da comparação entre lucros líquidos esperados, descontados dos totais dos bens de capital, em todos seus anos de uso aguardados. Incluiu entre os fatores determinantes a incerteza inseparável da expectativa. Myrdal não se referiu explicitamente à mutabilidade, que também deve ser inerente a qualquer variável ou programa dependente da expectativa. Para Wicksell, entretanto, ainda segundo Shackle ([1972] 1976, p. 357), foi a "taxa monetária" a que mais era propensa a variar, posto que se via afetada pelas circunstâncias e respostas variadas do sistema bancário. Mas Wicksell ([1911], 1986, p. 283) advertiu que a "taxa de juros natural” estava também sujeita a mudanças, às vezes muito intensas.

Shackle ([1967] 1991, p. 96) era entusiasta da "novidade radical do empreendimento de Myrdal", ao ter originado os conceitos ex ante e ex post. "Pela primeira vez, uma teoria econômica se baseava na construção imaginativa dos homens de um futuro desconhecido. O próprio Myrdal não o expressa assim, contentando-se em referir a antecipações e a suas incertezas. Porém, a mudança dramática e inflexível de fundamento teria que ser vista no seu significado pleno. A visão da econo- 
mia como uma contrapartida da mecânica celestial estava sendo abandonada. A diferença, em natureza e essência, entre o passado de qualquer momento e o futuro daquele momento, a não determinação do último pelo primeiro, exceto, no máximo, através dos pensamentos dos homens mal fundamentados em conhecimento apenas parcialmente relevante e bastante insuficiente, contrastava completamente com um modelo de ações individuais pré-reconciliadas, com um modelo de equilíbrio geral onde o mercado leva as ações dos homens a uma coerência racional, assim como o mar traz os navios ao mesmo nível”.

Myrdal, de acordo com Shackle, libertou a teoria econômica da premissa tácita e limitadora de que a economia se move como os planetas, em caminhos conhecidos cada qual na sua totalidade, independentemente do ponto no qual dado planeta se encontra no momento em que estamos calculando sua órbita. $\mathrm{O}$ futuro não é conhecido para aqueles cujas decisões, no seu efeito conjunto e na sua interação, o determinam.

$\mathrm{O}$ que se imagina para período por vir, em última instância, como elo em corrente de impulsos, tem que ajudar a configurar o que, ex post, surgirá como os fatos desse período. A concepção, em seu conjunto, foi capaz de afastar a massa de confusões que provinha do tratamento dos assuntos econômicos como se fossem algo mecânico ou hidráulico, em vez de ser subjetivo e psíquico. A Teoria Quantitativa da Moeda é hidráulica. Para deixar impressão (marca) no preço, segundo esta teoria, o dinheiro (liquidez) tem que chegar ao lugar (nível) no qual se troca efetivamente por bens. Se estiver em patamar inferior, o nível geral dos preços abaixa até encontrá-lo. Se superior, sobe.

A distinção que faz Myrdal entre a visão ex ante e a visão ex post, na opinião de Shackle ([1972] 1976, p. 455), foi um dos discernimentos mais transformadores que já ocorreram na economia teórica. Acha que esta noção foi traço de gênio. Para ele, o livro de Myrdal estabelece avanço teórico tão grande quanto o do próprio Wicksell e fornece inovação ainda maior. "Não existe nisto nenhum paradoxo. Todo escritor precisa começar com aparelhamento ou mesmo esquema de ideias preconcebidas. De fato, é óbvio que escrever in vacuo, começar inventando ideias que não devem nada a ninguém do passado é inconcebível ou poderia ser somente um trabalho de louco que, se ele o realizasse, não comunicaria nada ao mundo exterior. Uma ideia pode apresentar elemento de novidade poderosa, mas precisa também apresentar aspectos familiares, caso contrário ela não significaria nada para nós, ela poderia encontrar lugar no nosso pensamento, ela não poderia se ligar a nenhuma estrutura conceitual nossa ou mesmo pertencer à própria linguagem" (Shackle, [1967] 1991, p. 120).

No entanto, para a maioria dos homens, o apego a determinada ideia, uma vez entendida e familiarizada, é demasiadamente forte. A construção de nova teoria (como uma Teoria Alternativa da Moeda) requer, antes de mais nada, questionamen- 
to e libertação da velha teoria (a Teoria Quantitativa da Moeda), e todos os hábitos, instintos e indolências lutam contra tal libertação (Costa, 1999, pp. 3-32).

$\mathrm{Na}$ opinião de Shackle, exceto pelas colocações de ênfases, o Monetary Equilibrium de Myrdal antecipou em tudo a General Theory de Keynes. "Foi sua paixão por ideias exatamente formuladas, claras, quantificáveis e bem identificadas que permitiu que Myrdal, ao aplicá-la às sugestões poderosas de Wicksell, dissesse, em 1931, em sueco, muito das coisas que Keynes iria dizer em 1936, em inglês. [...] se a General Theory nunca tivesse sido escrita, o trabalho de Myrdal teria fornecido eventualmente quase a mesma teoria" (Shackle, [1967] 1991, pp. 121-123).

Sugere, então, linha contínua de pensamento que parte de Wicksell, passa por Myrdal, chega até Keynes. No entanto, na teoria de Wicksell-Myrdal, a resposta principal ao fortalecimento geral da demanda é aumento nos preços; na concepção de Keynes, a resposta é aumento do emprego e das produções físicas.

A prática de Keynes ocorreu de acordo com método não diacrônico, em que negava a estabelecer explicitamente qualquer marco formal de ideias acerca do tempo. Evidentemente, essa metodologia contrastou com o recurso da Escola de Estocolmo de analisar sequências de períodos. A aparente ortodoxia metodológica de Keynes, em seu tratamento ou menosprezo do tempo, para Shackle ([1972] 1976, p. 457), proporcionou meio a seus exegetas para desviar também seu significado até algo muito semelhante à economia convencional.

A ênfase dada à argumentação de Shackle é porque ela articula a Escola de Estocolmo e a Escola Pós-Keynesiana. Propõe, para esta, fazer releitura de Keynes, mas seguindo o método dinâmico dos pós-wicksellianos, como será visto, na próxima seção.

\section{RELEITURA DE KEYNES PELO MÉTODO PÓS-WICKSELLIANO}

Em 1937, Ohlin (1937, p. 54) chamou a atenção para os leitores da língua inglesa sobre as surpreendentes similaridades entre o aparato teórico e as conclusões alcançadas na Suécia e por Keynes, na Teoria Geral. Este ponto de confluência crítica à teoria clássica da moeda foi alcançado partindo-se de heranças teóricas distintas: wickselliana, de um lado, marshalliana, de outro.

Até que ponto as decisões econômicas são influenciadas pela antecipação de acontecimentos futuros, ou seja, pelas expectativas? Segundo Ohlin, o que Keynes faz das expectativas, na Teoria Geral, em muitos aspectos é semelhante à análise da Escola de Estocolmo. Sua principal crítica ao método de Keynes é que ele faz caso omisso da diferença fundamental existente entre as visões ex-post e ex-ante. A simples comparação entre duas situações de equilíbrio, de acordo com seu método estático comparativo, é incapaz de ter em conta a influência da rapidez das distintas reações dos agentes econômicos. "A distinção essencial entre o ex ante e 
o ex post, devida à Escola Sueca, teria esclarecido enormemente o pensamento de Keynes se ele estivesse familiarizado com ela" (Shackle, [1966] 1981, p. 53).

$\mathrm{Na}$ resposta à crítica de Ohlin, Keynes (1937b: 165) fez promessa que acabou sendo frustrada por sua doença e pela guerra mundial. Anunciou artigo, que pretendia escrever, lidando com a relação entre a análise ex ante e ex post e a análise de sua Teoria Geral. "Se Keynes tivesse sido poupado pelos eventos para escrever a 'quarta edição', aqui esboçada, da grandiosa concepção iniciada no Treatise, remodelada na General Theory e poderosamente destilada no seu artigo publicado no Quarterly Journal [em 1937], muito provavelmente teria surgido uma síntese incomparável e ter-se-ia dissipado a massa de confusão, criada em parte pelo próprio Keynes e parcialmente pelos críticos que se agarraram em falhas de exposição e expuseram a sua própria cegueira à essência de algo radicalmente novo" (Shackle, [1967] 1991, p. 222).

Assumindo o "método sueco", Shackle expressa, em sua essência, a pura doutrina keynesiana. Porém, de maneira não feita pelo próprio Keynes, ou seja, em termos de intenções, isto é, em linguagem ex ante. Assim, o desemprego seria devido ao malogro dos agentes econômicos em garantir a tempo o conhecimento de cada uma das demais "intenções condicionais" ou das reações potenciais. Ele é devido a conflito implícito de intenções. De um lado, há as intenções dos recebedores de renda de poupar grande parte das suas rendas, que receberiam no pleno emprego. De outro, essas pretensões não são acompanhadas pela intenção dos homens de negócios de comprar grande parte correspondente ao conjunto de sua própria produção, para o melhoramento líquido de seu equipamento.

Em suma, o desemprego involuntário é devido às decisões independentes. Há ignorância de agentes econômicos quanto às reações potenciais de cada um dos demais a esta ou àquela situação. Falta conhecimento das circunstâncias da própria ação de cada qual. Em economia monetária, tal emparelhamento dos desejos é muito mais distante que em economia de troca direta, pois a moeda atuando como reserva de valor permite o diferimento de gastos. Qualquer identidade ex post, por exemplo, a Equação de Trocas de Fisher que expressa a Teoria Quantitativa da Moeda, nada diz a respeito do problema de como dispor o dinheiro no lugar certo no exato momento para a execução de planos, intenções, decisões.

A proclamação de Shackle é para os pós-keynesianos abandonarem a Teoria Quantitativa da Moeda e considerarem a alternativa, à que ele chama de "teoria keynesiana”, ainda que sua origem possa ser localizada no economista sueco Knut Wicksell. Essa longa tradição crítica seria mais bem denominada de Teoria Alternativa da Moeda (Costa, 1999, pp. 3-32). Em sua opinião, “em alguns aspectos importantes, a General Theory não é apenas aprofundamento ou elucidação do Treatise, mas constitui-se também em desvio deste. O Treatise é inteiramente wickselliano. [...] a análise de período, a tentativa de se apresentar os eventos como sendo consequência das interações de decisões anteriores e as decisões subsequen- 
tes com sendo o resultado desses eventos, foi o que surgiu da 'crítica imanente' e da reformulação de Wicksell feitas por Myrdal e Lindahl. No entanto, na General Theory, Keynes seguiu uma outra direção. A General Theory é expressa em termos de uma comparação de equilíbrios" (Shackle, [1967] 1991, pp. 175 e 177).

Amadeo (1986, p. 122) também concorda que "os teóricos monetários mais eminentes das décadas de 1920 e 1930 utilizaram o mesmo método que Keynes empregou no Tratado sobre a Moeda, e que todos pertenceram à tradição pós-wickselliana — tradição da qual Keynes se afasta na Teoria Geral".

\section{CONCLUSÃO}

A Teoria Alternativa da Moeda segue o método dinâmico pós-wickselliano, pois entre seus postulados estão: a necessidade de validação monetária ex post de decisões econômicas e financeiras tomadas ex ante, a oferta de moeda endógena, isto é, atendendo ex post à demanda de crédito ex ante, e a não neutralidade da moeda. Esta afeta decisões ex ante, tornando os resultados ex post não correspondentes às expectativas anteriores. Esse método foi apresentado pela Escola de Estocolmo.

Somente depois de escrever a Teoria Geral, confrontado no debate com essa Escola, Keynes percebeu a noção fundamental desse método, isto é, decisões e escolhas se referem a ações ainda não realizadas. Portanto, sua tentativa de teorizá-las deveria ter se baseado em método essencialmente ex ante. Os pós-keynesianos, a partir das sugestões de Shackle, de fato, retomam a trajetória metodológica dinâmica. Carvalho (1989, p. 184-187), por exemplo, coloca como fundamentos da Escola Pós-Keynesiana os axiomas da inexistência de pré-conciliação, da irreversibilidade do tempo e da incerteza.

A conclusão, considerando ainda a ligação da obra principal de Keynes com a Teoria Quantitativa da Moeda, é que a Teoria Alternativa da Moeda, certamente, não pode ser estritamente "keynesiana", mas mais propriamente "pós-keynesiana”, ou melhor, "pós-wicksellina”, ou mesmo "pós-thorntoniana”... Henry Thornton inaugurou, em 1802, longa tradição antiquantitativista na história do pensamento econômico.

\section{REFERÊNCIAS BIBLIOGRÁFICAS}

AMADEO, Edward J. (1986). Teoria e método nos primórdios da macroeconomia (II): a tríade pós-wickselliana. Revista Brasileira de Economia. RJ, V. 40, n. 2, abr.-jun.

BEAUGRAND, Philippe. Henry Thornton: Un Précurseur de J. M. Keynes. Paris, Presses Universitaires de France, 1981.

CARVALHO, Fernando Cardim de (1989). Fundamentos da Escola Pós-keynesiana: A Teoria de uma 
Economia Monetária. in AMADEO, E. J.. Ensaios sobre Economia Política Moderna: Teoria e História. São Paulo, Editora Marco Zero.

COSTA, Fernando Nogueira da (1999). Economia Monetária e Financeira: Uma Abordagem Pluralista. São Paulo, Makron Books.

HANSSON, Björn A. (1990). The Swedish Tradition: Wicksell and Cassel. in HENNINGS, K. \& SAMUELS, W. (ed.). Neoclassical Economic Theory: 1870 to 1930. Boston, Kluwer Academic Publishers.

HANSSON, Björn (1991). The Stockholm School and The Development of Dynamic Method. in SANDELIN, Bo (ed.). The History of Suedish Economic Thought. London/NY, Routledge. Chap. 7.

HICKS, John ([1939], 1984). Valor e Capital: Estudo Sobre Alguns Princípios Fundamentais da Teoria Econômica. São Paulo, Abril Cultural (Os Economistas).

HICKS, John (1965). Capital and Growth. Oxford, Oxford University Press.

HICKS, John ([1967] 1978). Perspectivas Econômicas: Ensaios sobre Moeda e Crescimento. RJ, Zahar.

KEYNES, John Maynard ([1936], 1983). A Teoria Geral do Emprego, do Juro e da Moeda. SP, Abril Cultural.

KEYNES, John Maynard ([1937a], 1987). Teorias Alternativas da Taxa de Juros. Literatura Econômica, 9 (2): 147-158. (artigo original publicado no Economic Journal,186: 245-252, June 1937).

KEYNES, John Maynard ([1937b], 1987). A Teoria ex-ante da Taxa de Juros. Literatura Econômica, 9 (2): 165-172. (artigo original publicado no Economic Journal,188: 663-669, December 1937).

LEIJONHUFVUD, Axel (1989). Natural Rate and Market Rate. in EATWELL, MILGATE \& NEWMAN (ed.). The New Palgrave: Money. UK, The MacMillan Press.

LINDAHL, Eric ([1939] 1946). Estudios sobre la Teoria del Dinero y del Capital. Madrid, M. Aguilar.

LUNDBERG, E. ([1937] 1955). Studies in the Theory of Economic Expansion. Reprinted in New York, Kelley \& Millman.

MYRDAL, Gunnar ([1931], 1965). Monetary Equilibrium. NY, Augustus M. Kelley, (original inglês de 1939).

OHLIN, Bertil (1937a). Some Notes on the Stockholm Theory of Savings and Investment. The Economic Journal. Vol. 47, n 185: 53-69, March 1937 (Part I) and n 186: 221-240, June 1937 (Part II).

OHLIN, Bertil (1937b). Teorias Alternativas da Taxa de Juros - Réplica. Literatura Econômica. 9(2):159-164, 1987. (artigo originalmente publicado no Economic Journal, $\mathrm{n}^{\circ}$ 187: 423-427, September 1937).

OSER, Jacob \& BLANCHFIELD, William (1989). História do Pensamento Econômico. SP, Atlas.

SCHUMPETER, Joseph A. ([1954] 1964). História da Análise Econômica. RJ/SP, Editora Fundo de Cultura. Vol. 3.

SHACKLE, G. L. S. ([1965] 1969). Um Esquema de Teoria Econômica. RJ, Zahar.

SHACKLE, G. L. S. ([1966] 1981). La Naturaleza del Pensamiento Económico: Escritos Escogidos (1955-1964). México, Fondo de Cultura Económica.

SHACKLE, G. L. S. ([1967] 1991). Origens da Economia Contemporânea: Invenção e Tradição no Pensamento Econômico (1926-1939) [The Years of the High Theory]. SP, Hucitec.

SHACKLE, G. L. S. ([1972] 1976). Epistemica y Economia Critica de las Doctrinas Economicas. Mexico, Fondo de Cultura Económica.

SIVEN, Claes-Henric (2002). Analytical Foundations of Erik Lindahl's Monetary Analysis, 1924-1930. History of Political Economy. 34:1; 111-153.

SIVEN, Claes-Henric (2006). Monetary Equilibrium. History of Political Economy. 38:4; 665-709.

SOROMENHO, Jorge E. C. (1986). Uma Análise da Evolução do Conceito de Equilíbrio Monetário no Pensamento Sueco. SP, Dissertação de Mestrado pela FEA-USP, 1986. 
STEIGER, Otto (1989). Monetary Equilibrium. in EATWELL, MILGATE \& NEWMAN (ed.). The New Palgrave: Money. UK, The MacMillan Press Ltd.

UHR, Carl G. (1991) in Bo Sandelin (ed.). The History of Swedish Economic Thought. London/NY, Routledge.

UHR, Carl G. (1962). Economic Doctrines of Knut Wicksell. LA, University of California Press.

WICKSELL, Knut ([1911] 1986). Lições de Economia Política. SP, Nova Cultural. 